\title{
Development and characterization of an injectable cement of nano calcium-deficient hydroxyapatite/ multi(amino acid) copolymer/calcium sulfate hemihydrate for bone repair
}

\author{
This article was published in the following Dove Press journal: \\ International Journal of Nanomedicine \\ 20 November 2013 \\ Number of times this article has been viewed
}

\author{
Xiaotong $\mathrm{Qi}^{\mathrm{I}}$ \\ Hong $\mathrm{Li}^{2}$ \\ Bo Qiao' \\ Weichao $\mathrm{Li}^{1}$ \\ Xinyan $\mathrm{Hao}^{2}$ \\ Jun $\mathrm{Wu}^{\prime}$ \\ Bao Su' \\ Dianming Jiang' \\ 'Department of Orthopedics, The \\ First Affiliated Hospital, Chongqing \\ Medical University, Chongqing, \\ People's Republic of China; ${ }^{2}$ School \\ of Physical Science and Technology, \\ Sichuan University, Chengdu, \\ People's Republic of China
}

\begin{abstract}
A novel injectable bone cement was developed by integration of nano calciumdeficient hydroxyapatite/multi(amino acid) copolymer (n-CDHA/MAC) and calcium sulfate hemihydrate $\left(\mathrm{CSH} ; \mathrm{CaSO}_{4} \cdot 1 / 2 \mathrm{H}_{2} \mathrm{O}\right)$. The structure, setting time, and compressive strength of the cement were investigated. The results showed that the cement with a liquid to powder ratio of $0.8 \mathrm{~mL} / \mathrm{g}$ exhibited good injectability and appropriate setting time and mechanical properties. In vitro cell studies indicated that MC3T3-E1 cells cultured on the n-CDHA/MAC/ $\mathrm{CSH}$ composite spread well and showed a good proliferation state. The alkaline phosphatase activity of the MC3T3-E1 cells cultured on the n-CDHA/MAC/CSH composite was significantly higher than that of the cells on pure $\mathrm{CSH}$ at 4 and 7 days of culture. The n-CDHA/MAC/CSH cement was implanted into critical size defects of the femoral condyle in rabbits to evaluate its biocompatibility and osteogenesis in vivo. Radiological and histological results indicated that introduction of the n-CDHA/MAC into CSH enhanced new bone formation, and the n-CDHA/ $\mathrm{MAC} / \mathrm{CSH}$ cement exhibited good biocompatibility and degradability. In conclusion, the injectable n-CDHA/MAC/CSH composite cement has a significant clinical advantage over pure CSH cement, and may be a promising bone graft substitute for the treatment of bone defects.

Keywords: calcium-deficient hydroxyapatite, multi(amino acid) copolymer, calcium sulfate hemihydrate, injectability, biocompatibility, osteogenesis
\end{abstract}

\section{Introduction}

Treatment of large bone defects is currently a significant challenge for orthopedic surgeons. Many efforts have been made to develop new bone graft substitutes in recent years, due to the inherent limitations of autografts and allografts. ${ }^{1,2}$ Nano hydroxyapatite possesses excellent biocompatibility and bioactivity and is thus widely applied for bone tissue engineering. ${ }^{3}$ However, its extensive clinical application is still limited by its poor degradability and brittle property. ${ }^{4}$ Biocompatible polymers are another suitable candidate for bone graft substitutes. However, this material also has several shortcomings, including uncontrollable degradation, induction of local adverse tissue responses, and rapid strength decay. ${ }^{5,6}$ In order to overcome the above-mentioned disadvantages of bioceramics and biopolymers, ceramic/polymer composite materials that mimic the unique structure of hydroxyapatite/collagen in natural bone have become a focus of current research. ${ }^{7-9}$

Recently, a degradable biocomposite of nano calcium-deficient hydroxyapatite/ multi(amino acid) copolymer (n-CDHA/MAC) has been developed in our laboratory. ${ }^{10}$
Correspondence: Dianming Jiang Department of Orthopedics, The First Affiliated Hospital, Chongqing Medical University, NO.I Youyi Road,

Yuzhong District, Chongqing 4000I6,

People's Republic of China

Tel +8623890 I 1212

Fax +8623890 I I2I 2

Email jdm571026@vip.163.com 
The composite consists of n-CDHA and an amide linkage copolymer. The n-CDHA inorganic component has a lower $\mathrm{Ca} / \mathrm{P}$ ratio than nano hydroxyapatite $(1.50$ versus 1.67$)$ and thus shows an improved degradability. ${ }^{11,12}$ The MAC that is composed of 6-aminocaproic acid and five amino acids exhibits good ductility and biocompatibility. ${ }^{13}$ Our previous works have suggested that the amide-calcium-amide linkage and hydrogen bond formed between n-CDHA and MAC endow this biocomposite with eligible mechanical strength (compressive strength in the range of 88-129 $\mathrm{MPa}$ ), degradability, cytocompatibility, and osteoconductivity. ${ }^{10-13}$ However, the n-CDHA/MAC composite material has relatively poor flexibility, which limits its application in repairing complex and irregular bone defects. Injectable composites are gaining increasing interest in the orthopedic field, as they can be delivered to the target site via a minimally invasive manner. The injectable system has many advantages such as shortening of operation time, minimizing unwanted tissue damage, and reducing hospitalization length and cost. ${ }^{14}$ Thus, we sought to develop an injectable form of the n-CDHA/ MAC composite.

Calcium sulfate hemihydrate $\left(\mathrm{CSH} ; \mathrm{CaSO}_{4} \cdot 1 / 2 \mathrm{H}_{2} \mathrm{O}\right)$, also known as plaster of Paris, has a long history of clinical utilization in treating bone defects. ${ }^{15-17}$ The ability of selfsetting in situ renders CSH easy to handle and suitable for different types of bone injury. $\mathrm{CSH}$ has been successfully introduced to the nano-hydroxyapatite/collagen composite to yield an injectable and self-setting in situ bone graft substitute. ${ }^{18}$ These findings encouraged us to integrate the n-CDHA/ $\mathrm{MAC}$ and $\mathrm{CSH}$, aiming to combine the advantages of each compound and produce a novel injectable bone cement. In this study, we evaluated the self-setting time, mechanical properties, biocompatibility, and osteogenesis of the new composite based on different ratios of n-CDHA/MAC and $\mathrm{CSH}$ both in vitro and in vivo.

\section{Materials and methods Synthesis of $n-C D H A / M A C /$ CSH composite}

The n-CDHA/MAC composite was synthesized by an insitu polymerization method as described previously. ${ }^{10}$ In brief, $105 \mathrm{~g}$ of 6-aminocaproic acid, $6 \mathrm{~g}$ of alanine, $7 \mathrm{~g}$ of phenylalanine, $1 \mathrm{~g}$ of glycine, $6 \mathrm{~g}$ of proline, $2 \mathrm{~g}$ of lysine, and n-CDHA slurry ( $5 \mathrm{~g}$ n-CDHA/100 mL water) were added to a reaction kettle with continuous stirring. The mixture was heated to $200^{\circ} \mathrm{C}$ for about 2 hours until the water was fully evaporated, and the mixture was melted. The reaction product was then kept at $21^{\circ} \mathrm{C}$ for 2 hours and at $220^{\circ} \mathrm{C}$ for 1 hour. After cooling to room temperature, the target composites were obtained. The reaction system was protected by a continuous flow of nitrogen gas to avoid undesirable oxidation reactions. Then, the resultant composite was physically mixed with the powder of $\mathrm{CSH}$ at different ratios. The mixture was extruded at $170^{\circ} \mathrm{C}$ using a twin-screw extruder, air-cooled, and pulverized using a mill into a powder of particle size in the range of 38 to $125 \mu \mathrm{m}$. The n-CDHA/ $\mathrm{MAC} / \mathrm{CSH}$ composites with different weight percentages of n-CDHA/MAC (ie, $10 \%, 20 \%, 30 \%$, and $40 \%$ ) were obtained and moistened by distilled water with a liquid to powder $(\mathrm{L} / \mathrm{P})$ ratio of $0.8 \mathrm{~mL} / \mathrm{g}$. The mixture was further molded into cylinders and disks before use.

\section{Characterization of n-CDHA/MAC/ $\mathrm{CSH}$ composite}

The composition and structure of the n-CDHA/MAC/CSH composite containing 30\% n-CDHA/MAC were characterized by X-ray diffraction (D/Max-250; Rigaku Corporation, Tokyo, Japan) and Fourier transform infrared spectroscopy (170SX FT-IR Spectrometer; Nicolet, Madison, WI, USA). To observe the morphology of the cement after setting, the cement sample was fractured in liquid nitrogen, and a cross-sectional specimen was prepared for scanning electron microscopy (SEM).

\section{Measurement of setting time}

The setting time of the cements with $0 \%-40 \%$ of $n-C D H A /$ MAC was measured by the Vicat needle test according to the international standard ISO9579-1989E under an environment of $98 \%$ humidity and $37^{\circ} \mathrm{C} .{ }^{19}$ The initial setting time was defined as the time from the start of mixing to the plunge of the light needle $(280 \mathrm{~g}, \Phi 1.13 \mathrm{~mm})$ into the paste and had a span of $5 \pm 1 \mathrm{~mm}$ to the tube bottom. The final setting time was defined as the time until the heavy needle (350 g, $\varnothing 2.0 \mathrm{~mm}$ ) no longer left a visible impression on the surface of the paste. The analysis of each sample was repeated five times, and the results were expressed as mean \pm standard deviation (SD).

\section{Compressive strength measurement}

The composite samples containing different amounts of n-CDHA/MAC were prepared in a cylindrical form $(\Phi 10 \times 12 \mathrm{~mm})$. The samples were placed in an incubator at $37^{\circ} \mathrm{C}$ and $100 \%$ humidity for 7 days. After incubation, the samples were measured for their compressive strength by using a mechanical testing machine (REGER 30-50; Shenzhen Reger Instrument Co., Ltd, Shenzhen, People's 
Republic of China) with $50 \mathrm{kN}$ load cells. The crosshead speed was $5 \mathrm{~mm} / \mathrm{minute}$, and the load was applied until the specimens were compressed to about $20 \%$ of their original height. The analysis of each sample was repeated five times, and the results were expressed as mean $\pm \mathrm{SD}$.

\section{Cell culture and preparation of $\mathrm{n}-\mathrm{CDHA} / \mathrm{MAC} / \mathrm{CSH}$-based disks}

MC3T3-E1 cells (a clonal osteogenic cell line derived from newborn mouse calvarial osteoblasts ${ }^{20}$ were cultured in alpha-modified Eagle's Minimum Essential Medium ( $\alpha$-MEM; HyClone; Thermo Fisher Scientific, Waltham, MA, USA) with 10\% fetal bovine serum (FBS; HyClone; Thermo Fisher Scientific) plus 1\% penicillin/streptomycin (Beyotime; Beyotime Institute of Biotechnology, Shanghai, People's Republic of China) at $37^{\circ} \mathrm{C}$ in a humidified $5 \% \mathrm{CO}_{2}$ atmosphere. The $\mathrm{n}-\mathrm{CDHA} / \mathrm{MAC} / \mathrm{CSH}$ cement and pure $\mathrm{CSH}$ cement were individually made into disks $(\Phi 12 \times 2 \mathrm{~mm})$ and sterilized by ethylene oxide gas. The disks were placed into 24-well plates and used for the following cell experiments. Blank culture plates were used as a control.

\section{Cell morphology}

The disks $(\Phi 12 \times 2 \mathrm{~mm})$ mentioned above were placed into 24-well plates and prewetted in the culture medium for 24 hours. After incubation, approximately $3 \times 10^{4}$ MC3T3-E1 cells were seeded onto the surface of each disk. After 3 days of culture, the cell/disk constructs were washed to clean away nonattached cells and fixed with $2 \%$ glutaraldehyde solution for 2 hours at room temperature, followed by dehydration through a graded series of ethanol. Finally, the specimens were freeze-dried in vacuum, sputter-coated with gold, and examined using a scanning electron microscope (Hitachi S-3000N; Hitachi, Tokyo, Japan).

\section{Measurement of alkaline phosphatase (ALP) activity}

As described above, approximately $3 \times 10^{4}$ MC3T3-E1 cells were seeded onto the surface of each disk. The cells were harvested on days 1, 4, and 7 and subjected to assessment of ALP activity, using the Alkaline Phosphatase Colorimetric Assay Kit (ImmunoWay Biotechnology Company; Newark, DE, USA) according to the protocol supplied by the manufacturer. Briefly, the adherent cells were collected and suspended in a cell lysis buffer containing $0.1 \%$ Triton-X100. Following three cycles of freezing/thawing, cell lysates were centrifuged at 3,000 rpm for 20 minutes at $4^{\circ} \mathrm{C}$ and the supernatant was collected for the assays of ALP activity. The absorbance at $405 \mathrm{~nm}$ was recorded using a microplate reader, and the ALP activity was calculated from a standard curve. Total protein content in the supernatant was determined by the bicinchoninic acid method using the Beyotime protein assay kit (Beyotime Institute of Biotechnology). ALP levels were normalized to the total protein content.

\section{Animals and surgery}

Ethical approval was obtained from the Animal Care and Ethics Committee of Chongqing Medical University of China. Forty-eight skeletally mature New Zealand White rabbits $(2.5-3.5 \mathrm{~kg})$ were used in this study for the establishment of critical size defects in the femoral condyle. The animals were anesthetized by intravenous injection of 3\% pentobarbital sodium (Gen-View Scientific; El Monte, CA, USA). A longitudinal incision of about $5 \mathrm{~cm}$ in the lateral distal femur was performed to expose the femoral condyle. A cavitary defect of $6.5 \mathrm{~mm}$ in diameter and $1 \mathrm{~cm}$ in depth was created by a micro-burr with a $6.5 \mathrm{~mm}$ tip and saline irrigation was used to minimize thermal damage. After washing, the $\mathrm{n}-\mathrm{CDHA} / \mathrm{MAC} / \mathrm{CSH}$ cement containing $30 \%$ n-CDHA/MAC and medical grade calcium sulfate slurry (Osteoset; Wright Medical Technology Inc, Oakbrook Terrace, IL, USA) was injected into the bone defect. The choice of $30 \%$ n-CDHA/MAC was mainly due to an optimal setting time and mechanical strength. The untreated cavitary defect served as a control. At weeks 4, 8, and 16 after surgery, the animals were sacrificed by administering an overdose of pentobarbital sodium and the bone specimens were harvested for further analysis.

\section{Micro computed tomography (micro-CT) analysis}

High-resolution images of all specimens were obtained using a micro-CT scanner (Viva CT40; SCANCO Medical AG, Brüttisellen, Switzerland) running at $70 \mathrm{kV}$ and $114 \mu \mathrm{A}$. The sagittal and coronal images were reconstructed in a three-dimensional format. The quality of new formed bone was analyzed by calculating the percent bone volume (bone volume/total volume $[\mathrm{BV} / \mathrm{TV}])$ and trabecular number (Tb.N) in the central region of circular bone defects using the manufacturer's software (SCANCO Medical AG).

\section{Histological analysis}

The bone specimens were fixed in 10\% buffered formaldehyde, dehydrated by increasing concentrations of ethanol, and embedded in poly(methyl methacrylate) without decalcification. The specimens were cut longitudinally into 
approximately $10 \mu \mathrm{m}$ sections and stained with the Van Gieson stain. The stained slides were observed under a light microscope (BX51; Olympus Corporation, Tokyo, Japan).

\section{Statistical analysis}

All data are presented as mean \pm SD. Statistical difference was analyzed using one-way analysis of variance and Tukey's multiple comparison tests. A value of $P<0.05$ was considered to be statistically significant.

\section{Results}

\section{X-ray diffraction analysis}

The X-ray diffraction patterns of the composite with $30 \mathrm{wt} \%$ n-CDHA/MAC, MAC, CSH, and n-CDHA are shown in Figure 1 . The peaks at $2 \theta=20.0^{\circ}$ and $23.8^{\circ}$ corresponded to the MAC (Figure 1B) and those at $2 \theta=14.8^{\circ}, 25.8^{\circ}, 29.8^{\circ}$, $31.9^{\circ}, 42.3^{\circ}, 49.4^{\circ}$, and $55.1^{\circ}$ corresponded to the $\mathrm{CSH}$ (Figure 1C). The peak positions at $2 \theta=11.5^{\circ}, 25.7^{\circ}, 31.8^{\circ}$, $32.7^{\circ}, 34^{\circ}, 39.7^{\circ}, 47.1^{\circ}, 49.6^{\circ}$, and $53^{\circ}$ shown in Figure 1D indicated an apatite structure (Figure 1D). All of the aforementioned peaks appeared in the X-ray diffraction profile of the n-CDHA/MAC/CSH composite (Figure 1A). Of note, the peaks at $2 \theta=25.7^{\circ}, 31.9^{\circ}$, and $49.3^{\circ}$ for $n-C D H A$ and $\mathrm{CSH}$ were overlapped. Taken together, these results indicate that the n-CDHA/MAC/CSH composite is composed of n-CDHA, $\mathrm{MAC}$, and $\mathrm{CSH}$, and each component in the basic crystal structure does not change.

\section{Infrared spectroscopy analysis}

Figure 2 shows infrared spectra of the composite with $30 \mathrm{wt} \%$ n-CDHA/MAC, MAC, CSH, and n-CDHA. The peak of MAC at $3,415 \mathrm{~cm}^{-1}$ represented the stretching vibration of nitrogen-hydrogen $(\mathrm{NH})$, and the bands between $2,935 \mathrm{~cm}^{-1}$ and 2,860 $\mathrm{cm}^{-1}$ were attributed to carbon-hydrogen $\left(\mathrm{CH}_{2}\right)$ vibration (Figure $2 \mathrm{~B}$ ). The band at $1,538 \mathrm{~cm}^{-1}$ belonged to the stretching vibration of carbon-nitrogen $(\mathrm{CN})$. The band at $1,638 \mathrm{~cm}^{-1}$ was assigned to carbonyl vibration $(\mathrm{C}=\mathrm{O})$. These peaks indicate an amide copolymer structure. The peaks of CSH at 1,619, 1,117, 669, 600, and $463 \mathrm{~cm}^{-1}$ were assigned to $\mathrm{SO}_{4}{ }^{2-}$. The stretching mode of $\mathrm{CSH}$ crystalline water was also observed at 3,601 and 3,556 $\mathrm{cm}^{-1}$ (Figure 2C). In terms of the infrared spectrum of n-CDHA (Figure 2D), the peaks at 3,570 and $605 \mathrm{~cm}^{-1}$ reflected the vibration of the hydroxyl $(\mathrm{OH})$ group, and the peaks at 566, 1,034, and $1,094 \mathrm{~cm}^{-1}$

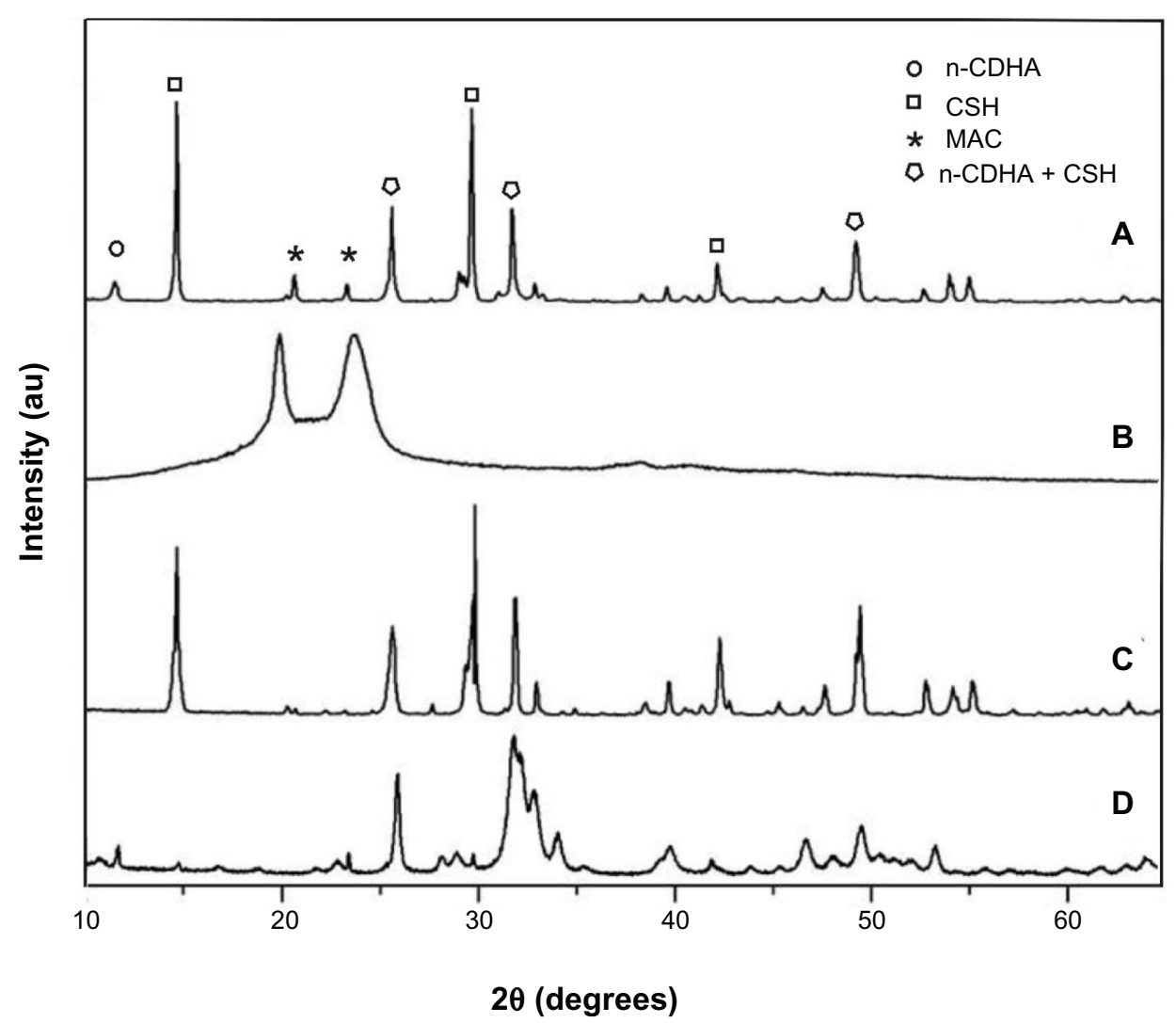

Figure I X-ray diffraction patterns of the composite cement with $30 \% \mathrm{n}-\mathrm{CDHA} / \mathrm{MAC}$ (A), MAC (B), CSH (C), and n-CDHA (D).

Abbreviations: $\mathrm{CSH}$, calcium sulfate hemihydrate; $\mathrm{n}-\mathrm{CDHA}$, nano calcium-deficient hydroxyapatite; $\mathrm{n}$-CDHA/MAC, nano calcium-deficient hydroxyapatite/multi(amino acid) copolymer; MAC, multi(amino acid) copolymer. 


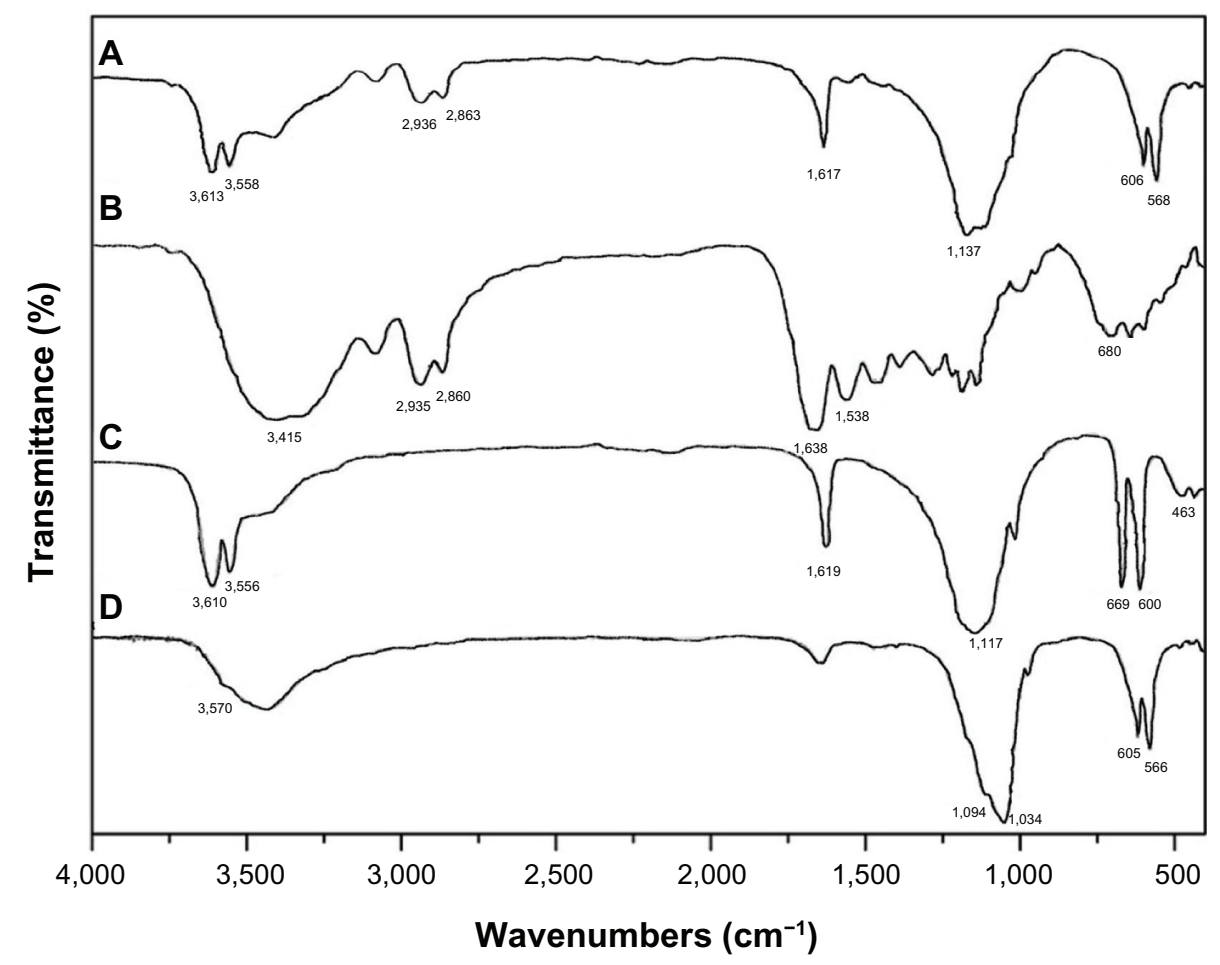

Figure 2 Infrared spectra of the composite cement with $30 \% \mathrm{n}-\mathrm{CDHA} / \mathrm{MAC}$ (A), MAC (B), CSH (C), and n-CDHA (D).

Abbreviations: $\mathrm{CSH}$, calcium sulfate hemihydrate; n-CDHA, nano calcium-deficient hydroxyapatite; n-CDHA/MAC, nano calcium-deficient hydroxyapatite/multi(amino acid) copolymer; MAC, multi(amino acid) copolymer.

corresponded to $\mathrm{PO}_{4}^{3-}$. These typical peaks of n-CDHA, $\mathrm{MAC}$, and $\mathrm{CSH}$ were detected in the infrared spectrum of the n-CDHA/MAC/CSH composite (Figure 2A), indicating that this composite is composed of the three components.

\section{Morphological characterization of $n-C D H A / M A C / C S H$}

The surface morphology of the n-CDHA/MAC/CSH composite containing 30\% $\mathrm{n}-\mathrm{CDHA} / \mathrm{MAC}$ and pure $\mathrm{CSH}$ observed by SEM is shown in Figure 3. As shown in Figure 3A and B, the pure CSH showed rod-like crystal morphology. In contrast, the n-CDHA/MAC/CSH composite exhibited a rough surface with some micropores of 100-200 $\mu \mathrm{m}$ in diameter (Figure 3C). Higher magnification images further revealed that $\mathrm{CSH}$ had been integrated into the n-CDHA/MAC matrix (Figure 3D).

\section{Self-setting properties}

We checked whether the ratio of $\mathrm{n}-\mathrm{CDHA} / \mathrm{MAC}$ to $\mathrm{CSH}$ affected the injectability of the n-CDHA/MAC/CSH composite. As shown in Figure 4, the setting time of the n-CDHA/MAC/CSH composite increased with the elevation in weight percentages of n-CDHA/MAC. The composite with $40 \% \mathrm{n}$-CDHA/MAC had a final setting time of over
60 minutes. In addition, the composite did not show any demixing or filter pressing during extrusion from the syringe. These results suggest that the proportion of $n-C D H A / M A C$ has a retarding effect on the setting time of the n-CDHA/ $\mathrm{MAC} / \mathrm{CSH}$ cement.

\section{Compressive strength measurement}

We also assessed the effects of the ratio of $\mathrm{n}-\mathrm{CDHA} / \mathrm{MAC}$ to $\mathrm{CSH}$ on the compressive strength of the n-CDHA/MAC/CSH composite. As shown in Figure 5, elevated percentages (up to $30 \%$ ) of the n-CDHA/MAC composition markedly increased the compressive strength of the n-CDHA/MAC/CSH composite after setting. However, when the weight percentage of the n-CDHA/MAC component reached $40 \%$, the compressive strength of the composite was significantly $(P<0.05)$ decreased as compared with that of $30 \%$ n-CDHA/MAC.

\section{Cell morphology}

SEM analysis revealed that after 3 days of culture, MC3T3-E1 cells spread well on the surface of both the n-CDHA/MAC/CSH composite with 30\% n-CDHA/MAC and pure $\mathrm{CSH}$ (Figure 6A and B). At day 7, the cultured MC3T3-E1 cells in each group aggregated with each other to form clusters (Figure 6C and D). 

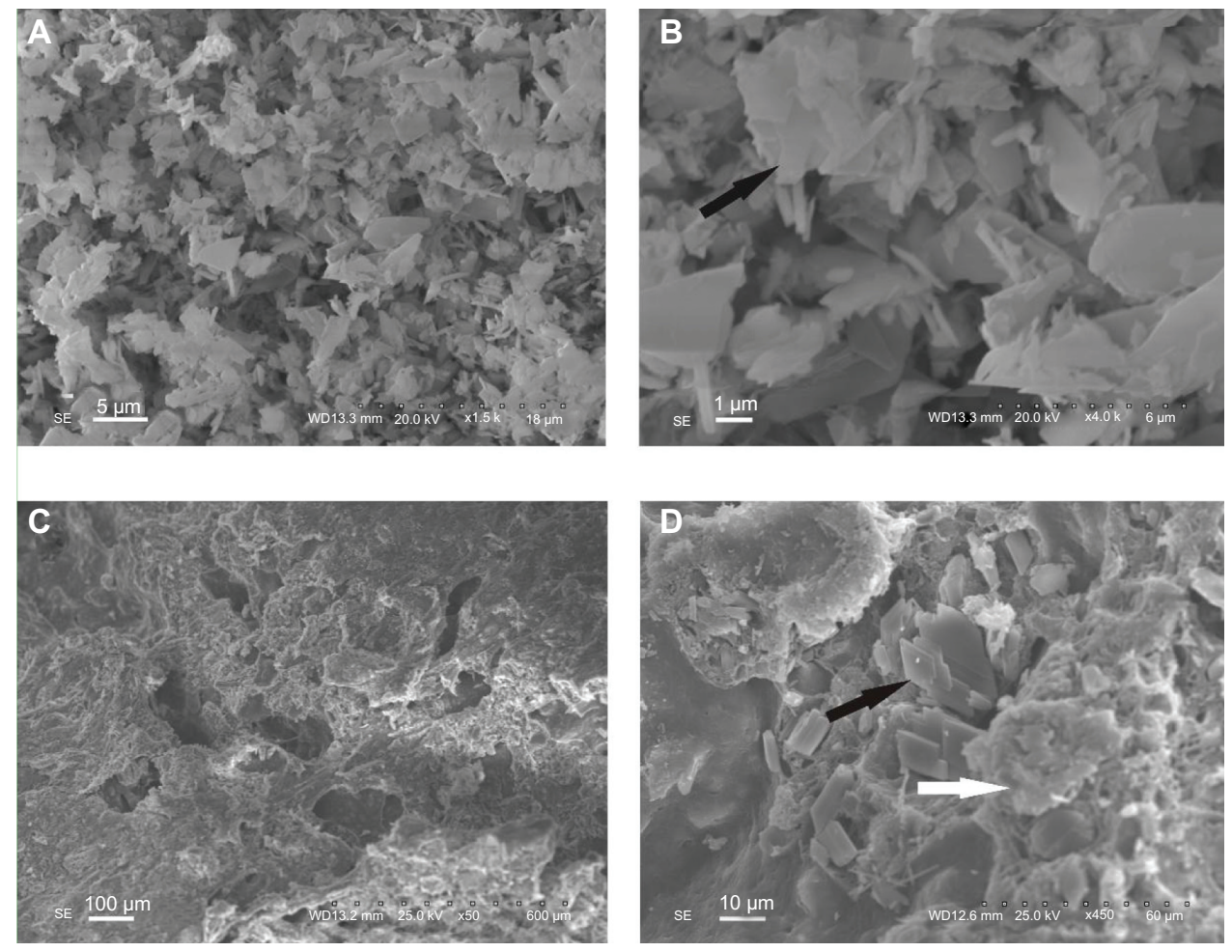

Figure 3 The surface morphology of the CSH (A and $\mathbf{B}$ ) and composite cement with 30\% n-CDHA/MAC (C and $\mathbf{D})$ determined by scanning electron microscopy. Notes: Black arrows indicate the CSH crystal, white arrows indicate the n-CDHA/MAC.

Abbreviatons: $\mathrm{CSH}$, calcium sulfate hemihydrate; $\mathrm{n}-\mathrm{CDHA} / \mathrm{MAC}$, nano calcium-deficient hydroxyapatite/multi(amino acid) copolymer.

\section{ALP activity}

The ALP activities of MC3T3-E1 cells cultured on the n-CDHA/MAC/CSH composite with 30\% n-CDHA/MAC and $\mathrm{CSH}$ (as a control) were assessed at days 1,4 , and 7 , and the results are shown in Figure 7. The ALP activity increased over time in all groups. No significant difference in the ALP activity was noted between the $\mathrm{n}-\mathrm{CDHA} / \mathrm{MAC} / \mathrm{CSH}$ composite with $30 \% \mathrm{n}-\mathrm{CDHA} / \mathrm{MAC}$ and $\mathrm{CSH}$ at day 1 . However, at days 4 and 7, the ALP activity in the n-CDHA/MAC/CSH group was significantly $(P<0.05)$ greater than in the control group.

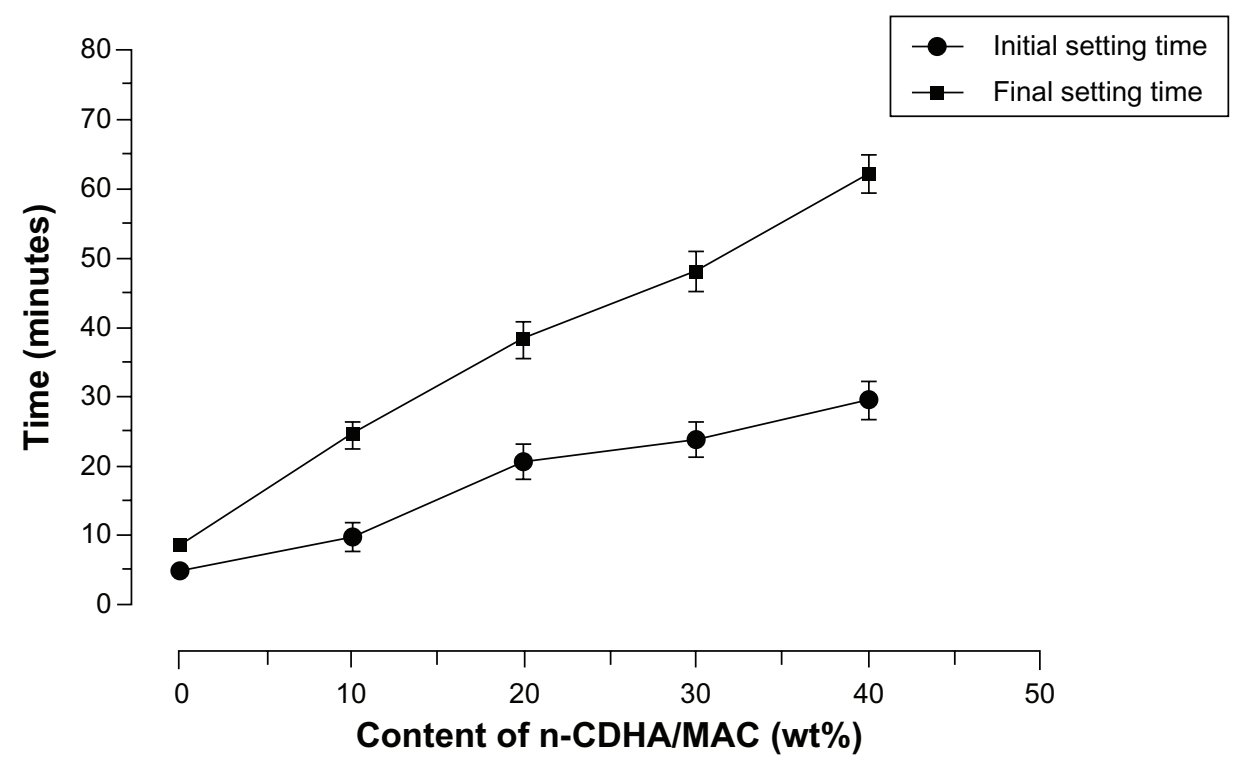

Figure 4 The setting time of the composites with different weight ratios of $n-C D H A / M A C$ and $\mathrm{CSH}$.

Abbreviations: $\mathrm{CSH}$, calcium sulfate hemihydrate; n-CDHA/MAC, nano calcium-deficient hydroxyapatite/multi(amino acid) copolymer. 


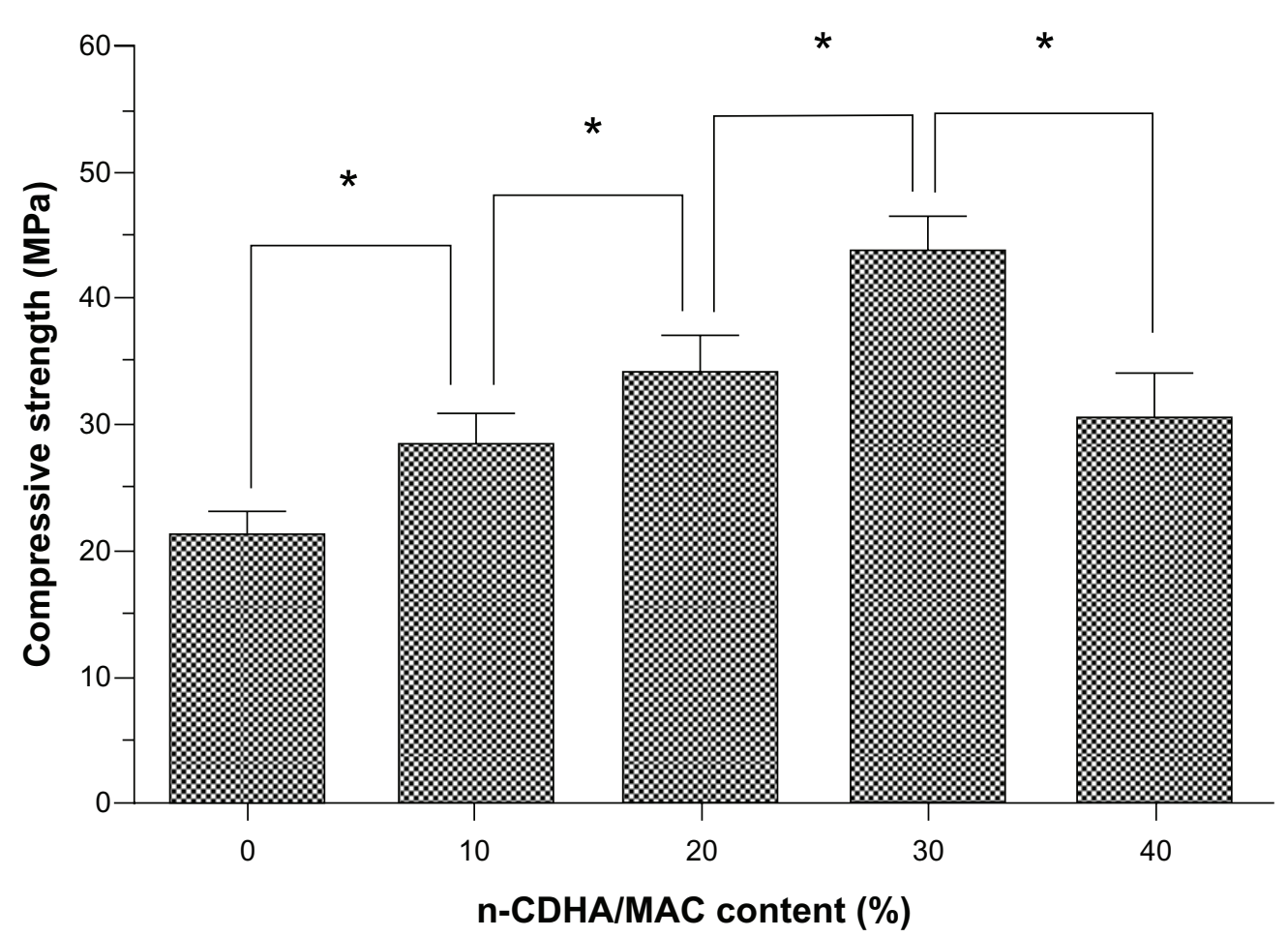

Figure 5 The compressive strength of the composites with different weight ratios of $n-C D H A / M A C$ and $C S H$. Note: $* P<0.05$.

Abbreviations: $\mathrm{CSH}$, calcium sulfate hemihydrate; n-CDHA/MAC, nano calcium-deficient hydroxyapatite/multi(amino acid) copolymer.
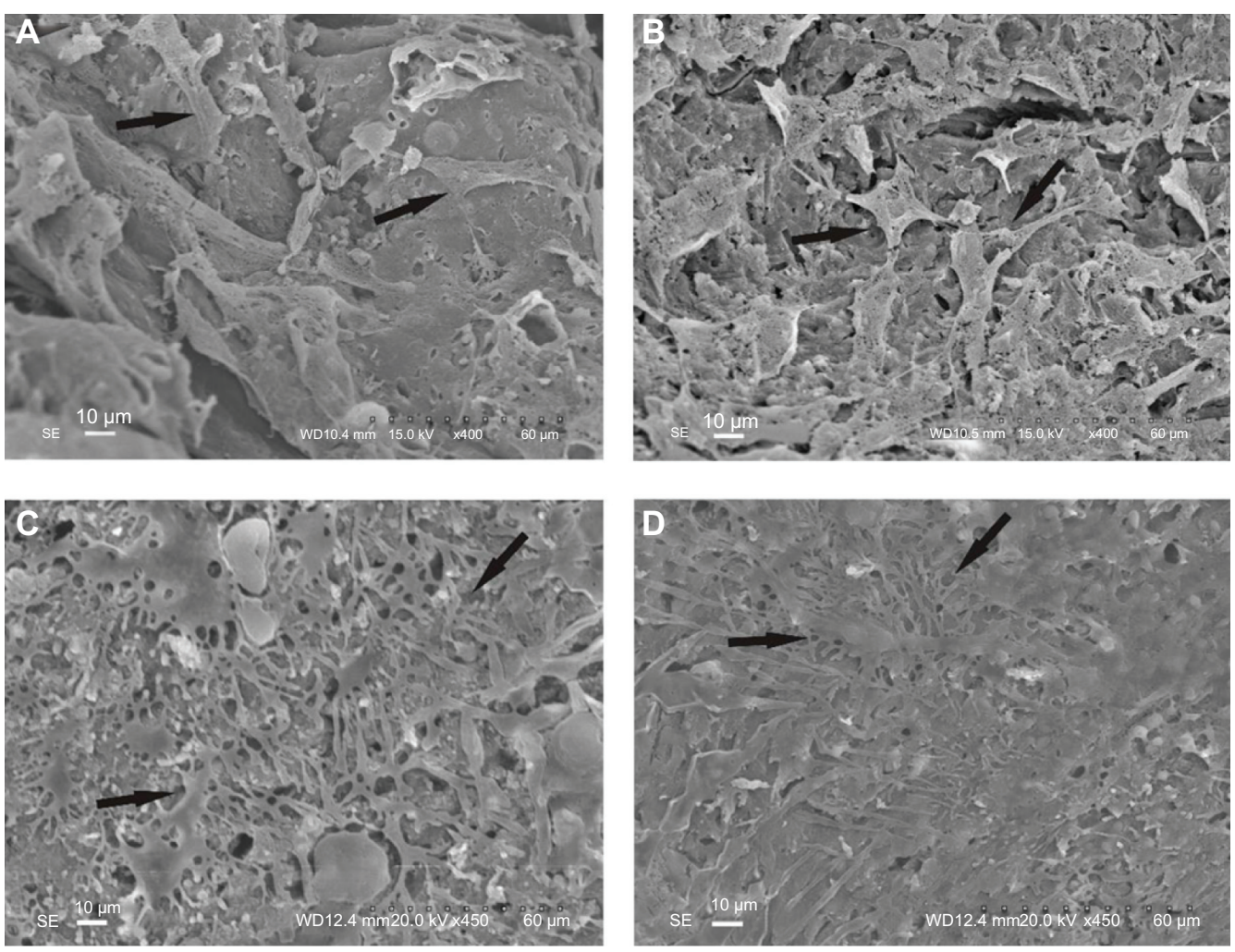

Figure 6 SEM micrographs of MC3T3-EI cells adhesion on the surface of n-CDHA/MAC/CSH and CSH after 3 days (A and $\mathbf{B})$ and 7 days $(\mathbf{C}$ and $\mathbf{D})$ of culture. Notes: (A and $\mathbf{C})$ n-CDHA/MAC/CSH; ( $\mathbf{B}$ and $\mathbf{D}) \mathrm{CSH}$. Arrows indicate the cells grown on the biocomposites.

Abbreviations: $\mathrm{CSH}$, calcium sulfate hemihydrate; $\mathrm{n}-\mathrm{CDHA} / \mathrm{MAC} / \mathrm{CSH}$, nano calcium-deficient hydroxyapatite/multi(amino acid) copolymer/calcium sulfate hemihydrate; SEM, scanning electron microscopy. 


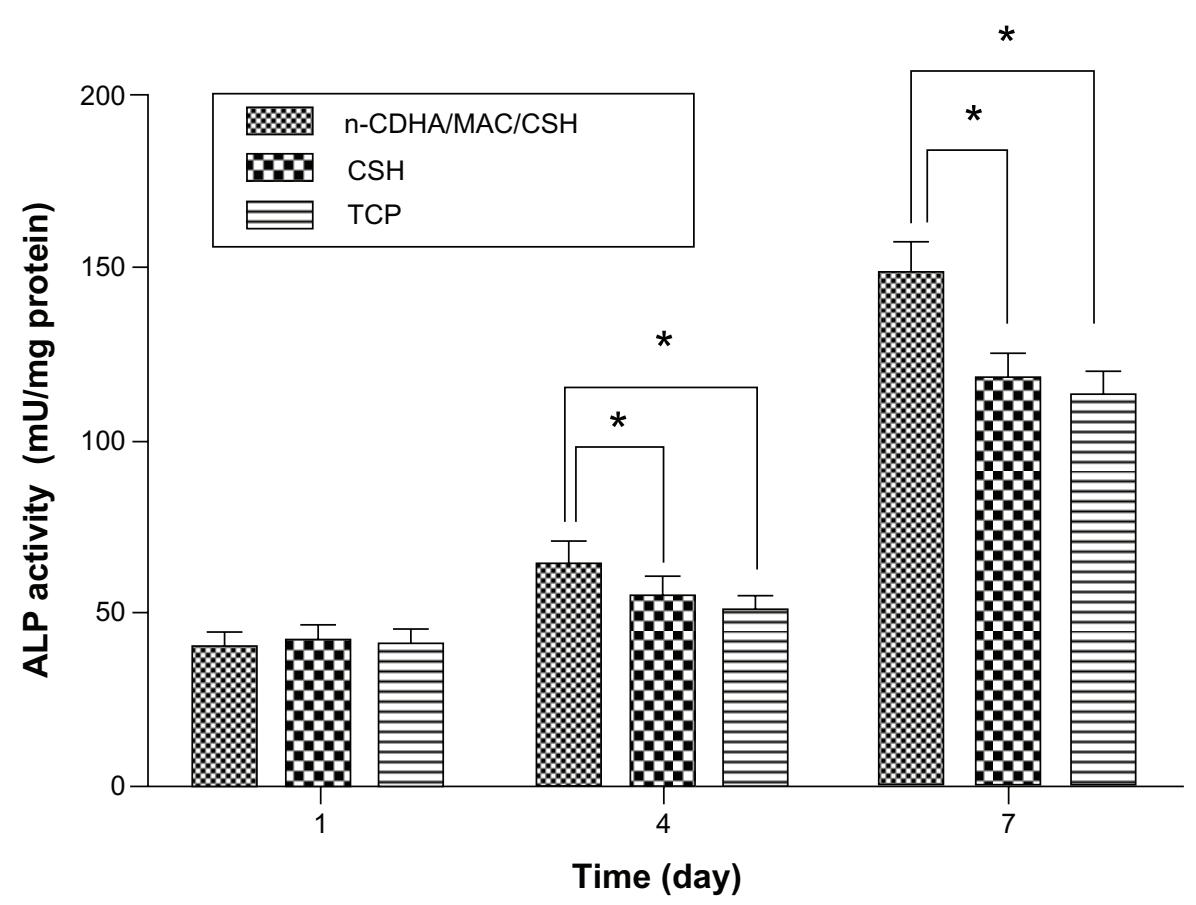

Figure 7 ALP activity of MC3T3-EI cells cultured on n-CDHA/MAC/CSH cement, CSH cement, and TCP as controls.

Note: $* P<0.05$.

Abbreviations: ALP, alkaline phosphatase; $\mathrm{CSH}$, calcium sulfate hemihydrate; $\mathrm{n}-\mathrm{CDHA} / \mathrm{MAC} / \mathrm{CSH}$, nano calcium-deficient hydroxyapatite/multi(amino acid) copolymer/ calcium sulfate hemihydrate; TCP, tissue culture plate.

\section{Micro-CT results}

The micro-CT scanning images of the repaired femoral condyles are shown in Figure 8. It can be seen in the specimens at week 4 post-implantation; the bone defects were filled with mineralized implants and new bone started to form in the n-CDHA/MAC/ $\mathrm{CSH}$ and CSH groups (Figure 8A and $\mathrm{B}$ ); we found no signs of healing in the untreated group (Figure 8C). At week 8, cortical parts of the n-CDHA/MAC/CSH- and CSH-treated bone defects were markedly restored with new bone. However, the bone cavity in the untreated group was visible at week 8 (Figure 8F). In the central area of the defect, the boundary between the implants and regenerated bone was indistinguishable (Figure $8 \mathrm{D}$ and $\mathrm{E}$ ). In the n-CDHA/MAC/CSH- and CSH-treated groups, the defects were completely repaired at week 16 . Moreover, the trabecular density as determined by visual inspection was higher in the $\mathrm{n}$-CDHA/MAC/CSH group than in the $\mathrm{CSH}$ group (Figure $8 \mathrm{G}$ and $\mathrm{H}$ ). As expected, the untreated group still showed an evident defect at the end of the experiment (Figure 8I).

To measure the amount and quantity of new bone formation, percent bone volume (BV/TV\%) and Tb.N in each group were determined by micro-CT analysis. As shown in Figure 9, $\mathrm{BV} / \mathrm{TV} \%$ and $\mathrm{Tb} . \mathrm{N}$ values increased from 4 to 16 weeks in all groups. The values of BV/TV\% and Tb.N in the n-CDHA/MAC/ $\mathrm{CSH}$ - and CSH-treated groups were significantly higher than the untreated group at each time point after implantation $(P<0.05)$.
Although there were comparable values between the n-CDHA/ $\mathrm{MAC} / \mathrm{CSH}-$ and $\mathrm{CSH}$-treated groups at week 4, a significant difference in $\mathrm{BV} / \mathrm{TV} \%$ was found at weeks 8 and 16 . Additionally, the n-CDHA/MAC/CSH-treated group had a significantly higher value of Tb.N at 4, 8, and 16 weeks after implantation, as compared to the $\mathrm{CSH}$-treated group $(P<0.05)$.

\section{Histological findings}

Representative micrographs of undecalcified bones from indicated groups at 4,8 , and 16 weeks after implantation are shown in Figure 10. In the n-CDHA/MAC/CSH-treated group, a small amount of newly formed bone grew into the inner site of the n-CDHA/MAC/CSH cement at week 4 postimplantation, coupled with generation of immature bone among it. More newly formed bone tissues were found at week 8 , while the volume of cement was decreased due to degradation. At week 16, the defects were completely repaired by mature trabecular bone, and there was only a small amount of residual nondegradable cement. The $\mathrm{CSH}$ cement displayed a rapid degradation compared to the $\mathrm{n}-\mathrm{CDHA} / \mathrm{MAC} / \mathrm{CSH}$ cement. The implanted CSH cement was divided into several small pieces at week 4 and almost completely degraded at week 8 . At week 16, the number and density of trabecular bone were markedly lower in the CSH-treated group than in the $\mathrm{n}-\mathrm{CDHA} / \mathrm{MAC} / \mathrm{CSH}$-treated group. 

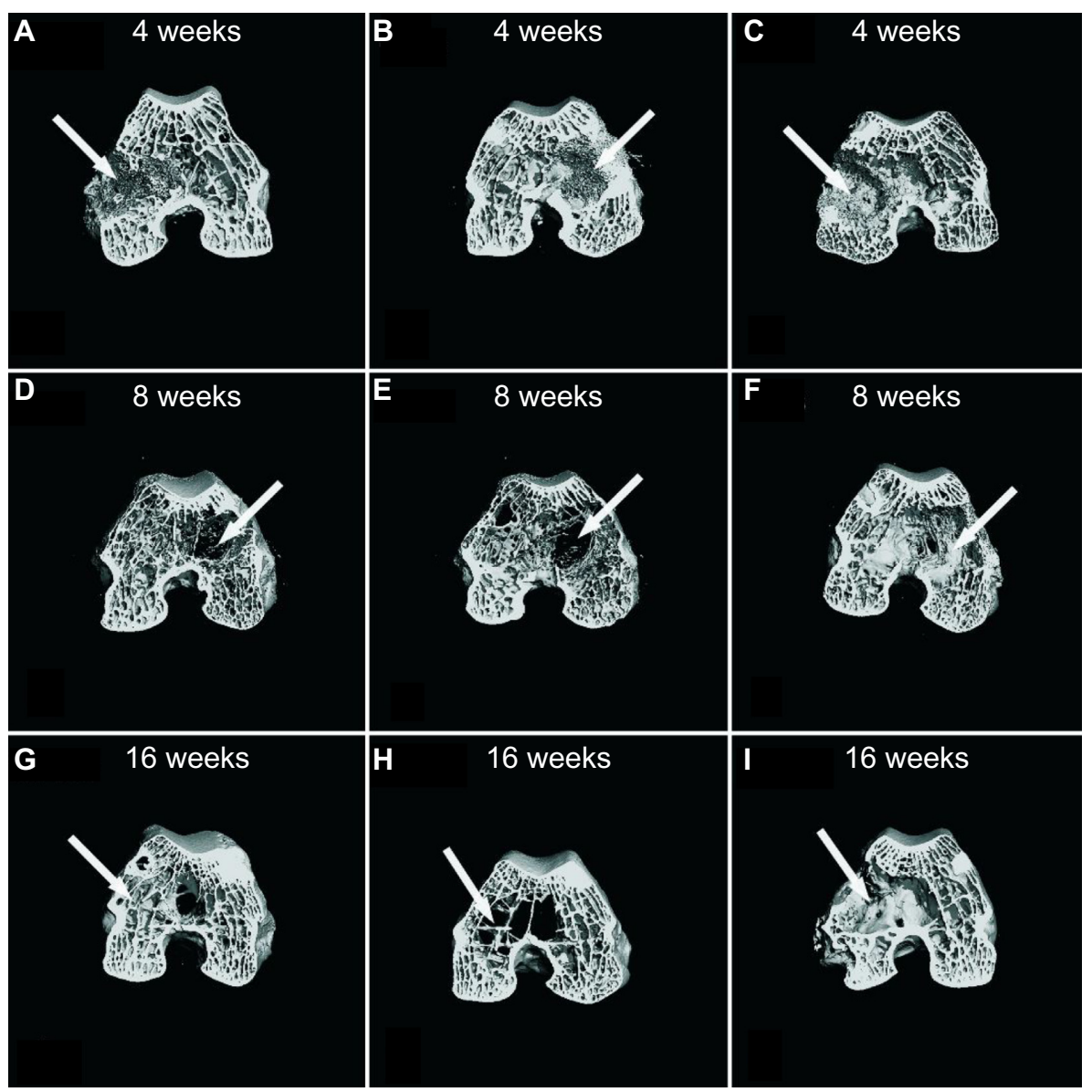

Figure 8 Representative coronal micro-CT images revealed the repair of bone defects in each group at postoperative 4, 8 , and I6 weeks: (A, D and $\mathbf{G}) \mathrm{n}-\mathrm{CDHA} / \mathrm{MAC} / \mathrm{CSH}$ cement group, (B, E and $\mathbf{H}) \mathrm{CSH}$ cement group, and (C, F and I) untreated control group.

Note: The arrow indicates the defect site.

Abbreviations: $\mathrm{CSH}$, calcium sulfate hemihydrate; $\mathrm{n}-\mathrm{CDHA} / \mathrm{MAC} / \mathrm{CSH}$, nano calcium-deficient hydroxyapatite/multi(amino acid) copolymer/calcium sulfate hemihydrate; micro-CT, micro computed tomography

\section{Discussion}

An ideal artificial bone graft substitute should have good biocompatibility, osteoinductivity, osteoconductivity, and biodegradability. ${ }^{21}$ Ceramic/polymer composite materials are considered to play an important role in bone regeneration. ${ }^{22}$ Recent studies have shown that $\mathrm{n}-\mathrm{CDHA}$ at a lower $\mathrm{Ca} / \mathrm{P}$ ratio (1.5-1.67) is more biologically active than the nano hydroxyapatite because the former has similar compositions and crystal structures to the mineral of nature bone. ${ }^{23,24}$ The addition of MAC to n-CDHA results in an improvement in the mechanical strength and ductility. However, the granular form of n-CDHA-MAC renders it difficult to be applied in irregular, complex bone injuries. In this study, we developed and characterized an injectable system based on n-CDHA-MAC and evaluated its application in treatment of bone defects.

The injectability and setting time greatly influence the applicability of an injectable self-setting biomaterial. Our present data revealed that compared with pure $\mathrm{CSH}$, the n-CDHA/
MAC/CSH composite shows a retarded setting time. The initial setting duration for the n-CDHA/MAC/CSH composites containing different proportions of $\mathrm{n}-\mathrm{CDHA} / \mathrm{MAC}$ varies from 10 to 30 minutes, which is consistent with previous studies. ${ }^{19,25}$ In contrast, the initial setting time for pure CSH is as short as 5 minutes. Clinically, the initial setting time of bone cements should be ideally controlled between 15-25 minutes. Taking into account that injectable cements must be delivered to bone defects before initial setting, the prolonged duration for selfsetting confers an apparent advantage in clinical applications. However, when the weight percentage of n-CDHA/MAC in the $\mathrm{n}-\mathrm{CDHA} / \mathrm{MAC} / \mathrm{CSH}$ composite is increased to $40 \%$ or more, the length of setting time is too long to meet the demands of surgery. Therefore, establishment of an optimal proportion of $n-C D H A / M A C$ is critical for developing the injectable n-CDHA/MAC/CSH system.

Mechanical strength is another important parameter for bone graft substitutes. Generally, the adult's compressive strength varies between 100 and $200 \mathrm{MPa}$ for cortical bone, 
A

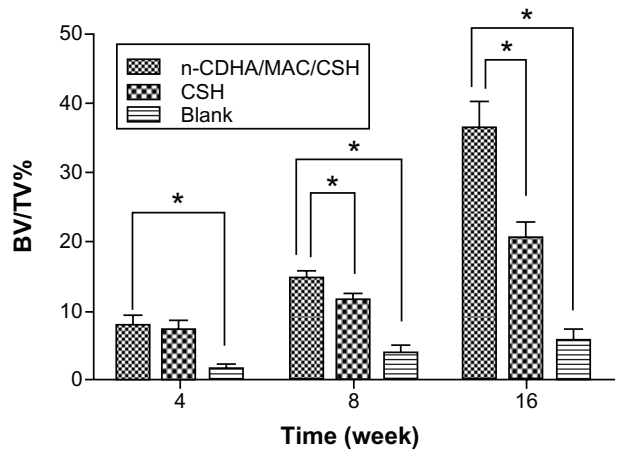

B

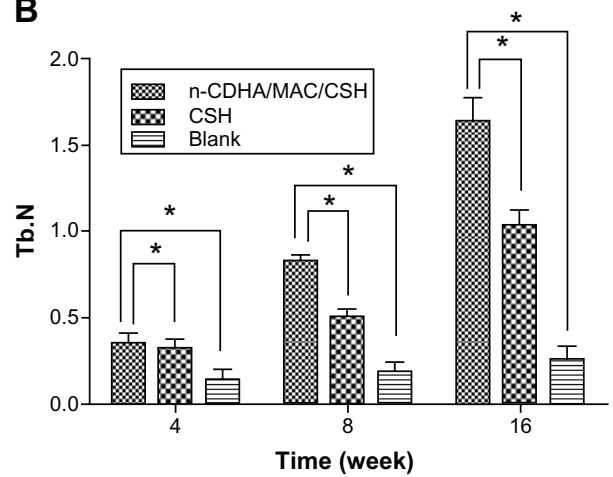

Figure 9 Quantitative analysis of bone defect repair at 4, 8, and 16 weeks after implantation with n-CDHA/MAC/CSH cement, CSH cement, or no cement filling (blank). Notes: (A) BV/TV\%; (B) Tb.N; $* P<0.05$.

Abbreviations: BV/TV\%, percent bone volume; $\mathrm{CSH}$, calcium sulfate hemihydrate; n-CDHA/MAC/CSH, nano calcium-deficient hydroxyapatite/multi(amino acid) copolymer/ calcium sulfate hemihydrate; Tb.N, trabecular number.

and between 2 and $20 \mathrm{MPa}$ for cancellous bone. ${ }^{26} \mathrm{We}$ found that after complete solidification, the compressive strength for the n-CDHA/MAC/CSH composite with 30\% n-CDHA/ MAC increases to about $45 \mathrm{MPa}$, indicating that this material is suitable for clinical use. It is noteworthy that when the n-CDHA/MAC concentration in the n-CDHA/MAC/ CSH composite reached $40 \%$, the compressive strength of this composite decreased instead of further increasing. This
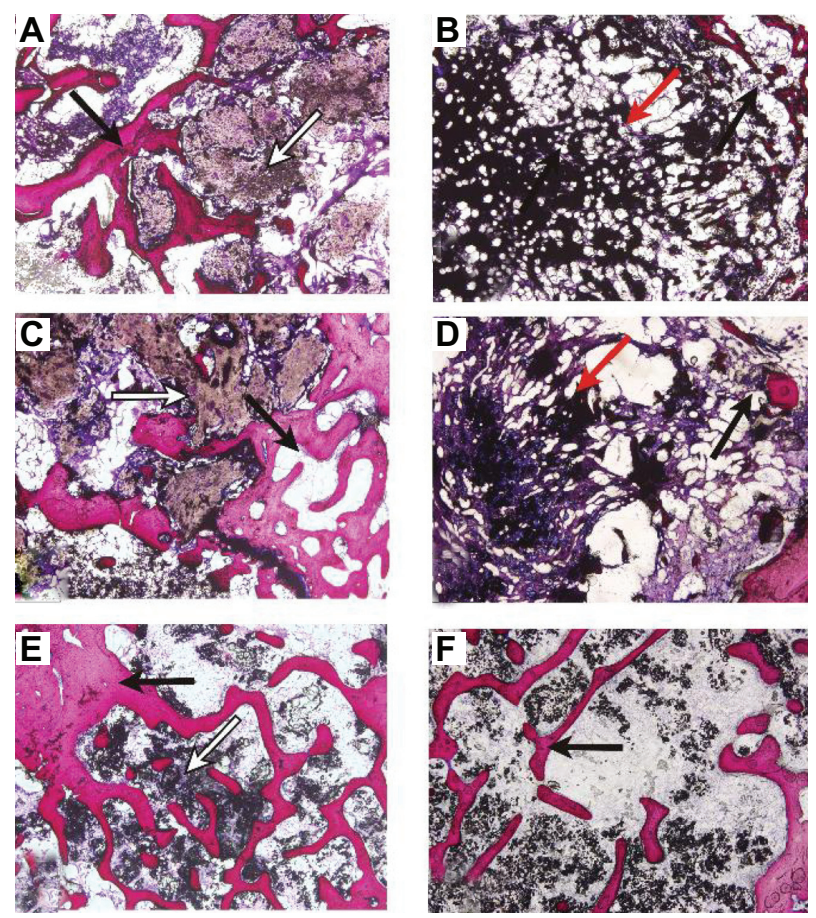

Figure 10 Van Gieson stained sections of n-CDHA/MAC/CSH cement (A, C and E) and CSH cement (B, D and F) harvested at 4 (A and B), 8 (C and D), and 16 (E and F) weeks post-implantation (magnification $40 \times$ ).

Notes: Black arrows denote newly formed bone tissue, white arrows denote n-CDHA/MAC/CSH cement, and red arrows denote CSH cement.

Abbreviations: $\mathrm{CSH}$, calcium sulfate hemihydrate; $\mathrm{n}-\mathrm{CDHA} / \mathrm{MAC}$, nano calciumdeficient hydroxyapatite/multi(amino acid) copolymer. may be explained by the mechanical strength of this composite being largely influenced by the self-transformation of $\mathrm{CSH}\left(\mathrm{CaSO}_{4} \cdot 1 / 2 \mathrm{H}_{2} \mathrm{O}\right)$ to calcium sulfate dihydrate (CSD; $\mathrm{CaSO}_{4} \cdot 2 \mathrm{H}_{2} \mathrm{O}$ ). Such transformation involves three main steps, ie, hydration, setting, and solidification. CSD crystals form an intertwined structure, which is regarded as a major source of mechanical strength. ${ }^{27}$ Inclusion of too much (eg,

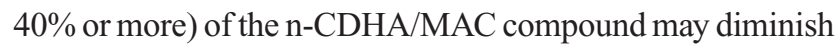
the production of CSD and form a loose complex structure, consequently leading to reduced compressive strength.

The ability to bond to osseous tissue is a vital index to evaluate the bioactivity of bioactive materials. Attachment, adhesion, and spreading in bone implants are required for osteogenic cells to proliferate and differentiate. ${ }^{28}$ The surface property of bioactive materials is thought to have an important influence on these cellular functions. As determined by the SEM analysis, we found that MC3T3-E1 cells spread well on both the n-CDHA/MAC/CSH composite and pure $\mathrm{CSH}$, suggesting an excellent bioactive property. It has been documented that the MAC containing $-\mathrm{COOH},-\mathrm{NH}_{2}$, and $-\mathrm{NH}-\mathrm{C}(\mathrm{O})$ groups can promote adsorption of adhesive proteins such as fibronectin and vitronectin, which help cells attach to the material. ${ }^{13,29}$ Therefore, the incorporation of n-CDHA into the MAC matrix may improve the biological properties of the composite material and has positive effects on cell proliferation and viability. ${ }^{24}$ ALP is an early marker for osteoblast differentiation and participates in the process of mineralization. ${ }^{30}$ Our data showed that the ALP activity in MC3T3-E1 cells cultured on the n-CDHA/ $\mathrm{MAC} / \mathrm{CSH}$ composite is significantly higher than in the cells cultured on pure $\mathrm{CSH}$ or control plates at 4 and 7 days of culture, indicating a promotion of osteogenesis by the n-CDHA/MAC/CSH composite. Taken together, the results 
demonstrate that the $\mathrm{n}-\mathrm{CDHA} / \mathrm{MAC} / \mathrm{CSH}$ composite has good biocompatibility.

A critical size defect is defined as the smallest tissue defect that would not completely heal during the lifetime of an animal. It has been suggested that critical size defects are suitable for testing bone repair materials or methods. ${ }^{31}$ In this study, a cancellous bone site was chosen for generation of bone defects due to the equilibrium between osteogenesis and biodegradation activities. ${ }^{32}$ Based on the above considerations, a critical size defect in the rabbit femoral condyle was used to evaluate the biocompatibility and osteogenesis of $\mathrm{n}-\mathrm{CDHA} / \mathrm{MAC} / \mathrm{CSH}$ composite in vivo. In rabbits, a $6 \mathrm{~mm}$ bone defect, which was established in this study, is generally regarded as the critical size defect. ${ }^{33}$ During the experiment, all the n-CDHA/MAC/CSH-treated rabbits remained in good health and did not show any fracture and wound complications. After sampling, no chronic inflammation and adverse tissue reactions were observed. These findings suggest that this composite exhibits excellent biocompatibility in vivo.

It has been documented that the addition of mineralized collagen (nano hydroxyapatite/collagen) improves the performance of $\mathrm{CSH}$ in bone regeneration. ${ }^{34}$ In agreement with this study, we also found that the n-CDHA/MAC/CSH implants accelerated new bone formation in the treatment of critical size defects, compared to the pure CSH implants. Moreover, the n-CDHA/MAC/CSH implant contacted with the host bone intimately, without causing any evident adverse effect on surrounding soft tissues. In contrast, no evident bone formation was detected in the untreated control group at the end of the experiment and, instead, the fibrous tissue grew into the defects. These findings suggest that the n-CDHA/ $\mathrm{MAC} / \mathrm{CSH}$ composite may prevent fibrous tissue in-growth into bone defects and guide bone repair effectively.

Biodegradability is another crucial factor for bone graft substitutes in bone tissue regeneration. An ideal bone graft substitute should be able to degrade with time in vivo, preferably at a controlled resorption rate and eventually creating space for the new bone tissue to grow. ${ }^{35}$ Previous studies reported that calcium sulfate resorption is nearly completed by 6 weeks, suggesting that it is not feasible for long-term clinical use. ${ }^{36,37}$ Our data revealed that in the n-CDHA/MAC/CSH-treated group, new bone regenerated and gradually penetrated into the cement, which was accompanied by the resorption of the cement. This cement was almost completely degraded until 16 weeks, when the bone defect was repaired. This suggests that the n-CDHA/MAC/CSH composite cement not only has good biocompatibility, but also appropriate biodegradability and osteoinductivity.

\section{Conclusion}

In summary, we developed a novel injectable composite cement by incorporating n-CDHA/MAC into the CSH matrix. The setting time and injectability of this composite material are significantly influenced by the weight ratio between the $\mathrm{CSH}$ and n-CDHA/MAC components. In vitro cell studies showed that the composite cement is more effective in promoting cell proliferation and adhesion of MC3T3-E1 osteogenic cells compared with pure CSH. Macroscopic observation of the composite cement implanted into the bone defects of rabbits did not cause undesirable tissue reactions such as inflammation and necrosis. Radiological and histological studies confirmed that the n-CDHA/MAC/ $\mathrm{CSH}$ composite cement facilitates new bone formation in vivo. These findings indicate that the injectable n-CDHA/ $\mathrm{MAC} / \mathrm{CSH}$ composite is a promising candidate for bone regeneration as a bone graft substitute, which shows good biocompatibility, bioactivity, and bioresorbability. Further studies are needed to investigate the feasibility of n-CDHA/ $\mathrm{MAC} / \mathrm{CSH}$ in other animal models and clinical settings and compare this novel composite with other clinically used bone cements.

\section{Acknowledgment}

This work is supported by the National Natural Science Foundation of China (81171685).

\section{Disclosure}

The authors report no conflicts of interest in this work.

\section{References}

1. Summers BN, Eisenstein SM. Donor site pain from the ilium. A complication of lumbar spine fusion. J Bone Joint Surg Br. 1989;71(4):677-680.

2. Wheeler DL, Enneking WF. Allograft bone decreases in strength in vivo over time. Clin Orthop Relat Res. 2005;(435):36-42.

3. Wang H, LiY, Zuo Y, Li J, Ma S, Cheng L. Biocompatibility and osteogenesis of biomimetic nano-hydroxyapatite/polyamide composite scaffolds for bone tissue engineering. Biomaterials. 2007;28(22):3338-3348.

4. LeGeros RZ, Lin S, Rohanizadeh R, Mijares D, LeGeros JP. Biphasic calcium phosphate bioceramics: preparation, properties and applications. J Mater Sci Mater Med. 2003;14(3):201-209.

5. Lackner JM, Jaccard J, Blanchard EB. Testing the sequential model of pain processing in irritable bowel syndrome: a structural equation modeling analysis. Eur J Pain. 2005;9(2):207-218.

6. Witte F, Calliess T, Windhagen H. [Biodegradable synthetic implant materials: clinical applications and immunological aspects]. Orthopade. 2008;37(2):125-130. German.

7. Wei G, Ma PX. Structure and properties of nano-hydroxyapatite/polymer composite scaffolds for bone tissue engineering. Biomaterials. 2004;25(19):4749-4757. 
8. Cui Y, Liu Y, Cui Y, Jing X, Zhang P, Chen X. The nanocomposite scaffold of poly(lactide-co-glycolide) and hydroxyapatite surfacegrafted with L-lactic acid oligomer for bone repair. Acta Biomater. 2009;5(7):2680-2692.

9. Wang Z, Li M, Yu B, Cao L, Yang Q, Su J. Nanocalcium-deficient hydroxyapatite-poly (e-caprolactone)-polyethylene glycol-poly (e-caprolactone) composite scaffolds. Int J Nanomedicine. 2012;7: 3123-3131.

10. Li H, Gong M, Yang A, Ma J, Li X, Yan Y. Degradable biocomposite of nano calcium-deficient hydroxyapatite-multi(amino acid) copolymer. Int J Nanomedicine. 2012;7:1287-1295.

11. Guo H, Su J, Wei J, Kong H, Liu C. Biocompatibility and osteogenicity of degradable Ca-deficient hydroxyapatite scaffolds from calcium phosphate cement for bone tissue engineering. Acta Biomater. 2009;5(1): 268-278.

12. Fuchs S, Jiang X, Gotman I, et al. Influence of polymer content in Ca-deficient hydroxyapatite-polycaprolactone nanocomposites on the formation of microvessel-like structures. Acta Biomater. 2010;6(8): 3169-3177.

13. Li H, Yan Y, Wei J, et al. Bone substitute biomedical material of multi(amino acid) copolymer: in vitro degradation and biocompatibility. J Mater Sci Mater Med. 2011;22(11):2555-2563.

14. Constantz BR, Ison IC, Fulmer MT, et al. Skeletal repair by in situ formation of the mineral phase of bone. Science. 1995;267(5205): 1796-1799.

15. Borrelli J Jr, Prickett WD, Ricci WM. Treatment of nonunions and osseous defects with bone graft and calcium sulfate. Clin Orthop Relat Res. 2003;(411):245-254.

16. Urban RM, Turner TM, Hall DJ, Infanger S, Cheema N, Lim TH. Healing of large defects treated with calcium sulfate pellets containing demineralized bone matrix particles. Orthopedics. 2003; 26(Suppl 5):s581-s585.

17. Thomas MV, Puleo DA. Calcium sulfate: Properties and clinical applications. J Biomed Mater Res B Appl Biomater. 2009;88(2): 597-610.

18. Hu NM, Chen Z, Liu X, et al. Mechanical properties and in vitro bioactivity of injectable and self-setting calcium sulfate/nano-HA/collagen bone graft substitute. J Mech Behav Biomed Mater. 2012;12:119-128.

19. Huan Z, Chang J. Self-setting properties and in vitro bioactivity of calcium sulfate hemihydrate-tricalcium silicate composite bone cements. Acta Biomater. 2007;3(6):952-960.

20. Sudo H, Kodama HA, Amagai Y, Yamamoto S, Kasai S. In vitro differentiation and calcification in a new clonal osteogenic cell line derived from newborn mouse calvaria. J Cell Biol. 1983;96(1):191-198.

21. Khan Y, Yaszemski MJ, Mikos AG, Laurencin CT. Tissue engineering of bone: material and matrix considerations. J Bone Joint Surg Am. 2008;90 Suppl 1:36-42.
22. Rezwan K, Chen QZ, Blaker JJ, Boccaccini AR. Biodegradable and bioactive porous polymer/inorganic composite scaffolds for bone tissue engineering. Biomaterials. 2006;27(18):3413-3431.

23. Lin JH, Kuo KH, Ding SJ, Ju CP. Surface reaction of stoichiometric and calcium-deficient hydroxyapatite in simulated body fluid. J Mater Sci Mater Med. 2001;12(8):731-741.

24. Sponer P, Strnadová M, Urban K. In vivo behaviour of low-temperature calcium-deficient hydroxyapatite: comparison with deproteinised bovine bone. Int Orthop. 2011;35(10):1553-1560.

25. Liu X, Wang XM, Chen Z, et al. Injectable bone cement based on mineralized collagen. J Biomed Mater Res B Appl Biomater. 2010;94(1):72-79.

26. Bose S, Roy M, Bandyopadhyay A. Recent advances in bone tissue engineering scaffolds. Trends Biotechnol. 2012;30(10):546-554.

27. Nilsson M, Wielanek L, Wang JS, Tanner KE, Lidgren L. Factors influencing the compressive strength of an injectable calcium sulfatehydroxyapatite cement. J Mater Sci Mater Med. 2003;14(5):399-404.

28. Anselme K. Osteoblast adhesion on biomaterials. Biomaterials. 2000;21(7):667-681.

29. Pompe T, Keller K, Mothes G, et al. Surface modification of poly(hydroxybutyrate) films to control cell-matrix adhesion. Biomaterials. 2007;28(1):28-37.

30. Marom R, Shur I, Solomon R, Benayahu D. Characterization of adhesion and differentiation markers of osteogenic marrow stromal cells. J Cell Physiol. 2005;202(1):41-48.

31. Ma JL, Pan JL, Tan BS, Cui FZ. Determination of critical size defect of minipig mandible. J Tissue Eng Regen Med. 2009;3(8):615-622.

32. Lu JX, Gallur A, Flautre B, et al. Comparative study of tissue reactions to calcium phosphate ceramics among cancellous, cortical, and medullar bone sites in rabbits. J Biomed Mater Res. 1998;42(3):357-367.

33. Hollinger JO, Kleinschmidt JC. The critical size defect as an experimental model to test bone repair materials. J Craniofac Surg. 1990;1(1):60-68.

34. Liu HY, Liu X, Zhang LP, Ai HJ, Cui FZ. Improvement on the performance of bone regeneration of calcium sulfate hemihydrate by adding mineralized collagen. Tissue Eng Part A. 2010;16(6):2075-2084.

35. Williams DF. On the mechanisms of biocompatibility. Biomaterials. 2008;29(20):2941-2953.

36. Turner TM, Urban RM, Gitelis S, Haggard WO, Richelsoph K. Resorption evaluation of a large bolus of calcium sulfate in a canine medullary defect. Orthopedics. 2003;26(Suppl 5):s577-s579.

37. Stubbs D, Deakin M, Chapman-Sheath $\mathrm{P}$, et al. In vivo evaluation of resorbable bone graft substitutes in a rabbit tibial defect model. Biomaterials. 2004;25(20):5037-5044.
International Journal of Nanomedicine

\section{Publish your work in this journal}

The International Journal of Nanomedicine is an international, peerreviewed journal focusing on the application of nanotechnology in diagnostics, therapeutics, and drug delivery systems throughout the biomedical field. This journal is indexed on PubMed Central, MedLine, CAS, SciSearch $\AA$, Current Contents ${ }^{\circledR} /$ Clinical Medicine,
Dovepress

Journal Citation Reports/Science Edition, EMBase, Scopus and the Elsevier Bibliographic databases. The manuscript management system is completely online and includes a very quick and fair peer-review system, which is all easy to use. Visit http://www.dovepress.com/ testimonials.php to read real quotes from published authors. 